\title{
Syllabification of Bi-Consonantal Clusters Between Vowels in
}

\section{Albanian}

\author{
Artan Xhaferaj ${ }^{1}$ \\ ${ }^{1}$ Department of Albanian Language and Literature, Faculty of Humanities, "Ismail Qemali" University of Vlora, \\ Albania \\ Correspondence: Artan Xhaferaj, Department of Albanian Language and Literature, Faculty of Humanities, \\ "Ismail Qemali” University of Vlora, Vlorë 9401, Albania. E-mail: artanxhaferaj@yahoo.com
}

Received: May 7, 2018 Accepted: May 30, 2018 Online Published: June 21, 2018

doi:10.5539/ijel.v8n5p230 URL: https://doi.org/10.5539/ijel.v8n5p230

\begin{abstract}
Syllabification is one of the most complex issues in Albanian phonetics. An extensive treatment of the topic was made by Dodi (2004), who, thanks to a thorough acquaintance with the existing literature on the area, also clearly states the drawbacks of the main theories of the syllable, based on material from the Albanian language. However, despite the huge research carried out and the important results achieved, the positions of linguists on syllabification remain different. One reason for this is that linguistic literature lacks an established definition of the syllable as a linguistic unit. In the present research on syllabification, we support some of the existing rules by bringing new arguments and making some additions in order to make them more convincing, with a view to improving and simplifying their practical application. We focus on syllable boundary when there are two consonants between vowels, based on the Sonority Sequencing Principle, on the Syllable Contact Law, the Dispersion Principle, and the Maximum Onset Principle.
\end{abstract}

Keywords: phonetics, syllabification, sonority hierarchy, syllable boundary, intervocalic consonants

\section{Introduction}

As studies in the Phonetics field indicate, the Theory of Sonority, which is based on acoustic criteria, explains the essence of the syllable more clearly, and offers a better solution to the problem of syllable boundary, despite the criticism that it may attract. According to this theory, a syllable represents the joining of a more sonorous element with a less sonorous one (Dodi, 2004). The syllable sonority increases from the syllable onset towards its peak, and then it starts to gradually fall from the peak towards the coda. The ideal sonority profile for the syllable is thus low at the margins and high at the peak (Eddington et al. 2013a, p. 48). While this principle has exceptions and raises questions of interpretation, it expresses a strong crosslinguistic tendency, and represents one of the highest-order explanatory principles of modern phonological theory (Clements 1990, p. 284). Based on the work of Sievers (1881) and Jespersen (1904), Clements (1990, p. 285) gives this variant of the theory of sonority: Between any member of a syllable and the syllable peak, only sounds of higher sonority rank are permitted. In linguistic literature, the most sonorous sounds comprise the low vowels, whereas the voiceless stop consonants are the least sonorous. Based on Jespersen's classification, Dodi (2004) made a classification of Albanian speech sounds according to sonority increase, as follows: Voiceless stops $s_{1}<$ Voiceless fricatives $_{2}<$

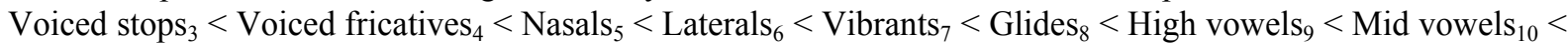
Low vowels ${ }_{11}$, where voiceless stops are the least sonorous and low vowels are the most sonorous.

A good example of the theory of sonority in the Albanian language is provided by monosyllable words with a syllable structure CCVCC, such as: krimb 'worm/caterpillar', kresht 'crest', krushk 'in-law', brisk 'razor', psalt 'preacher', prift 'priest', prind 'parent', trand 'shock', tremb 'scare', trung 'trunk', trust 'trust' etc. Thus, in the word prift 'priest', the first onset consonant is /p/, which has the lowest sonority in the speech sounds sonority frame; next comes the fricative $/ \mathrm{r} /$, which is more sonorous than $/ \mathrm{p} /$. Sonority keeps increasing towards the vowel /i/ (of maximum sonority), which represents the syllable nucleus, and then it starts to fall gradually to the syllable coda: first with the fricative /f/, which is more sonorous than the voiceless stop /t/ at the end of the word.

Clements (1990) noted that, at syllable onset level, large sonority differences are preferred over small ones, which goes to say that $/ \mathrm{pj}-/$ is a better onset than $/ \mathrm{lj}-/$, while in the rhyme small sonority differences are preferred 
over large ones, making /-j/ a better coda than /-t/ (Gussenhoven \& Jacobs 2011, p. 165). Apparently, according to Clements (1990), syllables prefer to start with a bang and end with a whimper, the reason being that the onset is highly important as it attracts the listener's attention when it should; presumably, this reason is perceptive. Syllables tend to sequence in words in such a way that the sonority of the end of one syllable is greater than that of the beginning of the next, favouring a whimper - bang transition over a bang - whimper one (Gussenhoven \& Jacobs, 2011). Such tendencies can be more clearly explained by the Syllable Contact Law. This law was first described by Vennemann (1972), then by Hooper (1976), Murray and Vennemann (1983), Clements (1990) etc. According to Murray and Vennemann (1983, p. 520), "the preference for the syllable structure $A \$ B$, where $A$ and $B$ are marginal segments and $a$ and $b$ are the sonority values of $A$ and $B$ respectively, increases with the value a minus $b$." This specification, according to Clements, extends the Syllable Contact Law over all kinds of syllable contacts, including V-C contacts. Consequently, sequences such as [ik-a] comprise the worst possible example of syllable contact, whereas [i-ka], the best. This law was rather more simply explained by Hooper (1976), and Clements (1990), who expressed it as: In every $C_{a} \$ C_{b}$ sequence, the preference is for $C_{a}$ to exceed $C_{b}$ in sonority. For example, the syllable boundary in the word [par-ket] 'parquet, flooring' goes between two consonants, because $/ \mathrm{r} /$ is more sonorous than $/ \mathrm{k} /$. Thus, according to Gussenhoven and Jacobs (2011) too, when we consider the relation between syllables, the tendency is to maximize the bang at the beginning. (Note 1)

According to Parker (2002), the authors who have treated the Syllable Contact Law have generally pointed out two necessary conditions in their analyses: first, the appropriate Syllable Contact Law is, in a way, expressed in the definition given by Murray and Vennemann; second, the condition that limits the application of this rule, known as Syllable Contact Slope (Bat-El, 1996; Shin, 1997; Davis, 1998), or Sonority Contour Slope (Rose, 2000), mediates the relative degree of syllable contact violation permitted in each language, normally in a gradient fashion. However, as Clements (1990) noticed, the Syllable Contact Law and the slope limitation are themselves connected with the Sonority Dispersion Principle. In order to make this principle more comprehensive, Clements presents the notion of the demisyllable: A syllable is divided into two overlapping parts called demisyllables; the syllable nucleus belongs to both parts simultaneously. According to this author, the demisyllable is a maximal of the tautosyllabic segments in the form of $C_{m} \ldots C_{n} V$, or $V_{m} \ldots C_{n}$, where $n \geq m$ $\geq 0$. The fundamental idea of using the term demisyllable is that the sonority profile of the first part of the syllable is independent of the sonority profile of its second part. Thus, the "sonority dispersion" feature can be best determined on the demisyllable.

The dispersion principle according to Clements (1992):

\section{a. The preferred initial demisyllable maximally increases sonority dispersion; \\ b. The preferred final demisyllable minimizes sonority dispersion.}

Here is an illustrating example in Albanian. In the monosyllabic word qan 'cries', the initial demisyllable on the left is [qa], while the second (or final) demisyllable, on the right, is [an]. In the first demisyllable, sonority rises from the plosive /q/ to the vowel /a/, having thus a maximal dispersion, whereas in the second demisyllable, there is a smaller dispersion as sonority falls from the vowel /a/ to the nasal $/ \mathrm{n} /$.

Finally, another universal principle related to syllabification is the Maximum Onset Principle. Following this principle, consonants between vowels are maximally placed at syllable onset, bearing into consideration the language-specific conditions too. The Maximum Onset Principle, proposed by Kahn (1976), requires that the syllable onset be constructed firstly, as long as it is permissible, and then an acceptable coda be formed. According to Clements (1992, p. 73.), the Maximal Onset Principle requires that we take the demisyllable, rather than the cluster, as the domain of sonority constraints: e.g. VCV is syllabified preferentially as V-CV rather than as VC-V just because $\mathrm{V}$ is a simpler final demisyllable than $\mathrm{VC}$ and $\mathrm{CV}$ is a simpler initial demisyllable than $\mathrm{V}$, for any value of $\mathrm{C}$. In Albanian, for instance, according to this principle, the word liri 'freedom' would be divided into syllables as [li-ri] and not *[lir-i]; the word problemi 'the problem' would be divided as [pro-ble-mi] and not *[prob-le-mi] etc. The presence of the intervocalic consonant in the onset of second syllable, rather than in the coda of the first is universal (Gussenhoven \& Jacobs, 2011), which is why consonants prefer to be part of the onset rather than the coda, as long as the syllable structure has no restrictions.

\section{Methodology}

Through a comparative and analytic approach, we will analyze the syllable boundary of bi-consonantal clusters in intervocalic position in Albanian language. In the present research on syllabification, we support some of the existing rules by bringing new arguments and making some additions in order to make them more convincing, also based on some universal patterns of sonority, with a view to improving and simplifying their practical application. 
In order to get a view of the practical application of syllabification rules, we conducted a survey with one hundred 9 to 10-year-old schoolchildren at two secondary schools in the town of Vlora: forty-four participants were from "Muço Delo" Secondary School and fifty-six from "Ismail Qemali" Secondary School. We were present in class to explain the nature of the survey. The children who volunteered to do so were given a list of words containing consonant clusters in intervocalic position. If a student happened to forget a word, they were given the paper back again for them to complete it instantly. The detailed outcomes of the questionnaire are presented in Appendix A.

\section{Syllabification}

Based on these phonetic principles or universal patterns of sonority, more certain analyses can be conducted in the Albanian language in order to determine syllable boundary, and more sustainable solutions can be offered for controversial instances of consonantal clusters in intervocalic position.

Syllable boundary determination is generally more difficult with a group of two obstruents or two sonorants between two vowels than with the group obstruent + sonorant and sonorant + obstruent between vowels. In the cases of obstruent + sonorant pairs between vowels, the consonants join with the subsequent vowel to form a syllable (Dodi, 2004). This case is perfectly compatible with the sonority theory. However, the rule: "when there are two or more consonants between vowels, they will go together if there are words in the language which start with that string of consonants; otherwise, they will be divided" contributes to worsening disagreements on syllable boundary determination.

Let us illustrate this with the words misra 'maize fields' and mishra 'meats' (Note 2). There are no words in Albanian starting with the string /sr/, but there are words starting with $/ \mathrm{shr} /$. Following this rule, the syllable boundary is between the consonants $/ \mathrm{s} /$ and $/ \mathrm{r} /$ in the word [mis-ra], whereas $/ \mathrm{sh} /$ and $/ \mathrm{r} /$ form a syllable with the subsequent vowel in the word [mi-shra]. In both cases there is a voiceless fricative followed by a vibrant sonorous between the two sonority peaks (the vowels /i/ and /a/), so there is the same listening perception. The Figure 1 shows the sonority curve of these two words. (Note 3 )

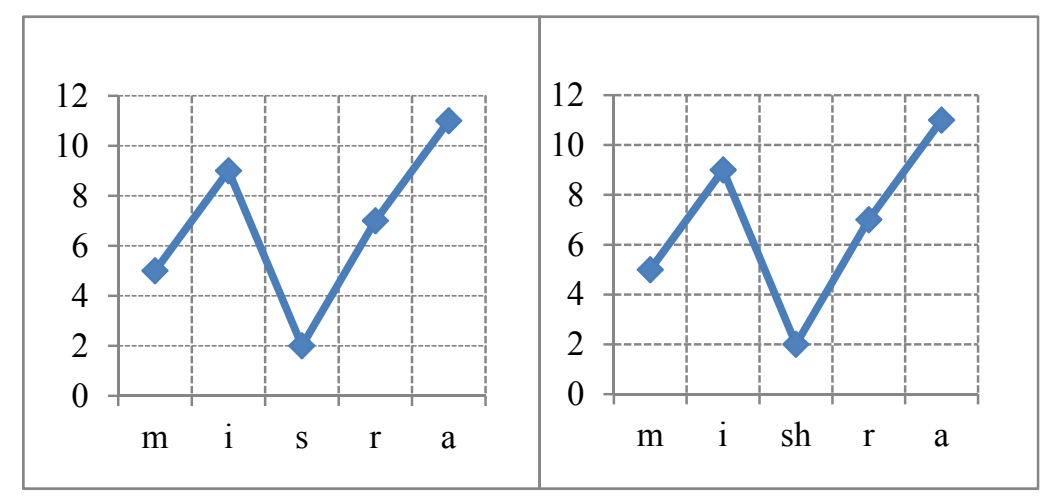

Figure 1. Sonority curve of the words misra and mishra

Dodi questions the value of the above rule by stating definitely that the word misri is divided as [mi-sri], even though no words in Albanian start with the string /sr/. The survey data indicate that the participants placed both groups, /sr/ (82\%) and /shr/ (70\%), in the onset of the second syllable. As Figure 1 clearly demonstrates, the sonority line slope is the same for both words, so, in our opinion too, their syllabication must also be the same: the obstruent + sonorant pair in intervocalic position should form a syllable with the subsequent vowel. In this way, the rule becomes more generalizing: it is in full agreement with both the Sonority Theory and the Maximum Onset Principle, thus providing us with open syllables too, which, according to Dodi (2004, p. 133), comprise the most common syllable pattern in Albanian.

Furthermore, the two-consonant group nasal sonorant + obstruent in intervocalic position forms a syllable with the subsequent vowel (Dodi 2004, p. 135). Yet there are more than fifteen two-consonant nasal + obstruent groups between vowels in Albanian with which no words in the language start (Xhaferaj 2014, p. 66). If we consider the words fanta 'a fruit juice brand' and banka 'the bank', their syllabic division would be: fan-ta and $b a-n k a$, as no Albanian words start with the string /nt/, but there are words starting with /nk/. We also emphasize that both $/ \mathrm{t} /$ and $/ \mathrm{k} /$ are of the same degree of sonority: they are both voiceless stops. That is why we do not consider it a correct, simple and practical solution that the string /nt/ should be divided, whereas the string /nk/ 
go with the subsequent vowel. The sonority slope of these two words is the same too (as Figure 2 shows). However, it is common knowledge that the acoustic signal produced in continuous articulation differs according to context. In a study on the acoustic features of consonants, R. Wright $(2004$, p. 52) notes that the only consonants to have reliable cues at their peaks of stricture are sibilant fricatives. This might be the reason why syllables of the type sCV are cross-linguistically common, even though they have a sonority reversal. According to Wright, the cues for /s/ in $\mathrm{sCV}$ are weaker than those for $\mathrm{C}$ in $\mathrm{CV}$, so there are also many languages that have $\mathrm{CV}$ but lack sCV. "If the place [of formation] is sacrificed, then nasals may also occur in sonority reversals: their manner cues are clear even in isolation, but their place cues will disappear, making them homorganic with the following obstruent" (Wright 2004, p. 52).

This phenomenon appears clearly in Albanian as the strings $m b, n d, n g, n g j, m p, n t, n k, n q$ are pronounced in a single articulation and appear as compound sounds. In such cases, the sonority slope is also more moderate than the one shown in Figure 2. For these reasons, we find Dodi's rule that the nasal + obstruent group between vowels forms a syllable with the following vowel more acceptable.

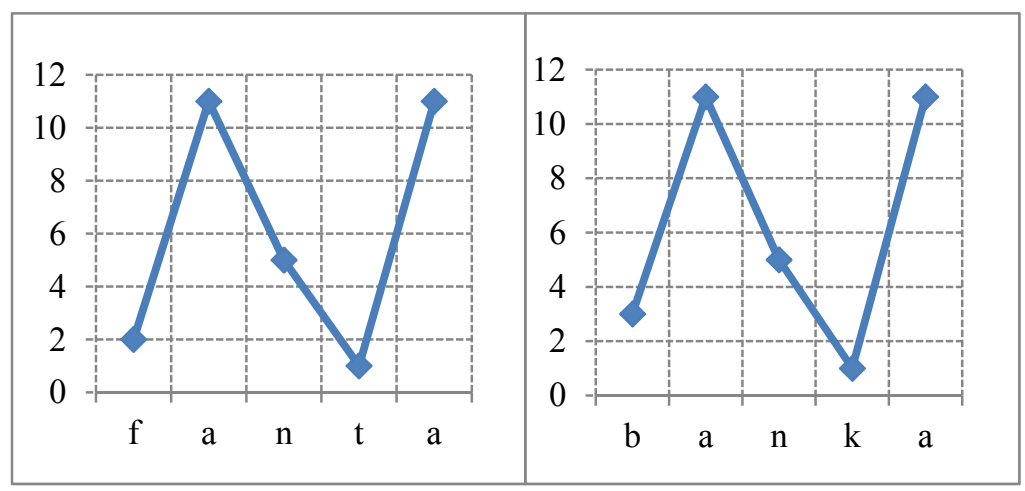

Figure 2. Sonority curve of the words fanta and banka

The two-consonant strings formed by other sonorant elements (vibrant, lateral, medial) + obstruent in intervocalic position are divided as these examples: por-ti 'port, seaport', pal-ca 'marrow', vaj-zë 'girl' etc. Such a syllabification of these words is in full agreement with the Syllable Contact Law, since the consonants $/ \mathrm{r} /, / 1 /$, $/ \mathrm{j} /$, appearing in coda position, are more sonorous than the consonants $/ \mathrm{t} /, / \mathrm{c} /$ and $/ \mathrm{z} /$, appearing in onset position, as well as with the Sonority Dispersion Principle, because there is a maximal sonority increase in the initial demisyllables [po, pa, va], whereas in the final demisyllables [or, al, aj] there is a reduced dispersion. The tendency for the first consonant in a cluster to be placed in the coda of the first syllable, if it is a sonorant, can be also acquainted in American English (Eddington et al. 2013b, p. 82).

Another controversial situation appears when we are to determine the syllable boundary for groups consisting of two obstruents between vowels in words such as pafka 'the stud' and nafta 'the petrol'. We have previously stated (2014, p. 63) that we do not consider it a correct or practical solution that the group /ft/ be divided in the word [paf-ka], as no word in Albanian starts with that group, while the group /ft/ form a syllable with the subsequent vowel in the word [na-fta], since there are words in the language starting with that group. Since these groups have the same listening perception, and their sonority slope in the intervocalic position is also the same as in Figure 3, the pattern of their syllabic division must be the same too. For these reasons we are supportive of the rule formulated by Dodi, according to which two obstruents between vowels should go with the second vowel to form a syllable. In this case too, the rule becomes more generalizing and it is in full conformity with the Maximum Onset Principle, as Albanian syllabic structure allows such consonant groups to appear in the onset. As to sonority reduction in syllables other than initial, we hold the view that it is (here) insignificant; furthermore, linguistic research holds that, in simpler gradations, obstruents arrange in the same sonority scale of sounds. Nevertheless, as we have also emphasized above, reversed sonority syllables are linguistically common (as sponge, star, skin in English; stein 'stone' in German; stylo 'pen' in French; stinë 'season' or brisk 'razor' in Albanian etc.) especially so in Albanian, in which nasal + obstruent groups (which have a more inclined slope, as Figure 2 shows), because of articulation properties, go with the subsequent vowel. Without doubt, such sonority slopes of these groups are related with their articulation convenience. 


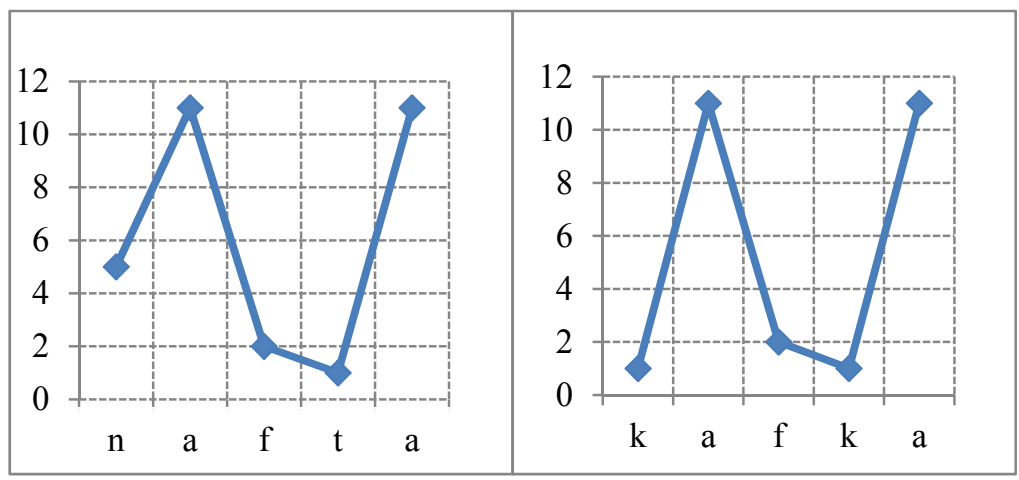

Figure 3. Sonority curve of the words nafta and kafka

There is also controversy on the syllable boundary for such words that contain two sonorous consonants. If we obey the phonotactic rule, the group /rj/ should be split in larje 'washing' because it is not in onset position, whereas the group /rrj/ should go with the subsequent vowel in the word marrje 'reception'. We must emphasize that $/ \mathrm{r} /$ and $/ \mathrm{rr} /$ are both vibrants. Our survey indicates that the students involved preferred to place the groups $/ \mathrm{rj} /$ $(64 \%)$ and $/ \mathrm{rrj} /(52 \%)$ in the onset of the second syllable. The fact that $48 \%$ of the participants place the consonant $/ \mathrm{rr} /$ in the onset of the second syllable may be accounted for by the articulation properties of [rr] and not by the morpheme boundaries, as both cases consist of a Past Participle (lar-, marr-) + a noun-forming suffix $(-j e)$. As we have argued for the previous cases, in these words too, their syllabification must be the same (la-rje, ma-rrje) because the intervocalic groups possess the same sonority slope, as can be seen in Figure 4.

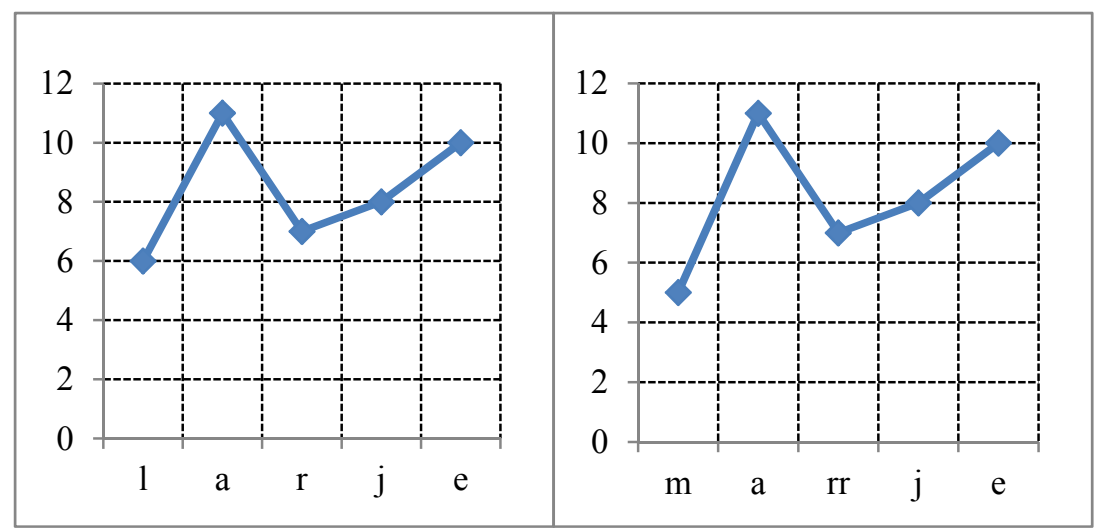

Figure 4. Sonority curve of the words larje and marrje

In respect of Dodi's valuable contribution, we shall re-examine the groups of two sonorous consonants in intervocalic position, making a few additions to make them more convincing. Thus, groups such as /-jm-/, / $-j l-/$ and $/-j r-/$, in which $/ \mathrm{j} /$ appears as a first constituent, are divided (e.g., laj-mi 'the news', gaj-le 'bothering', aj-ri 'the air'), whereas groups such as /-mj-/, /-rj-/, /-rrj-/, /-lj-/ and /-llj-/, in which /j/ appears as a second constituent, go with the subsequent vowel (e.g., pa-mje 'view', tha-rje 'drying', tje-rrje 'spinning', shku-lje 'up-rooting', sje-llje 'behavior'). Likewise, the groups /-rl-/, /-rm-/, /-rn-/, /-rnj-/, in which /r/ appears as a first constituent of the group (except for $/-\mathrm{rj}-/$, for $/ \mathrm{j} /$ is more sonorous than $/ \mathrm{r} /$ ), are divided (e.g., per-la 'the pearl', hur-ma 'the date fruit', bar-na 'medicines'), while the group /-mr-/ goes with the subsequent vowel (e.g., ze-mra 'the heart').

Unlike Dodi, however, we think that the group /-rl-/, in the same way as the group /-rm-/, must be divided in intervocalic position because they possess almost the same sonority slope (as Figure 5 shows for the words perla and hurma). 


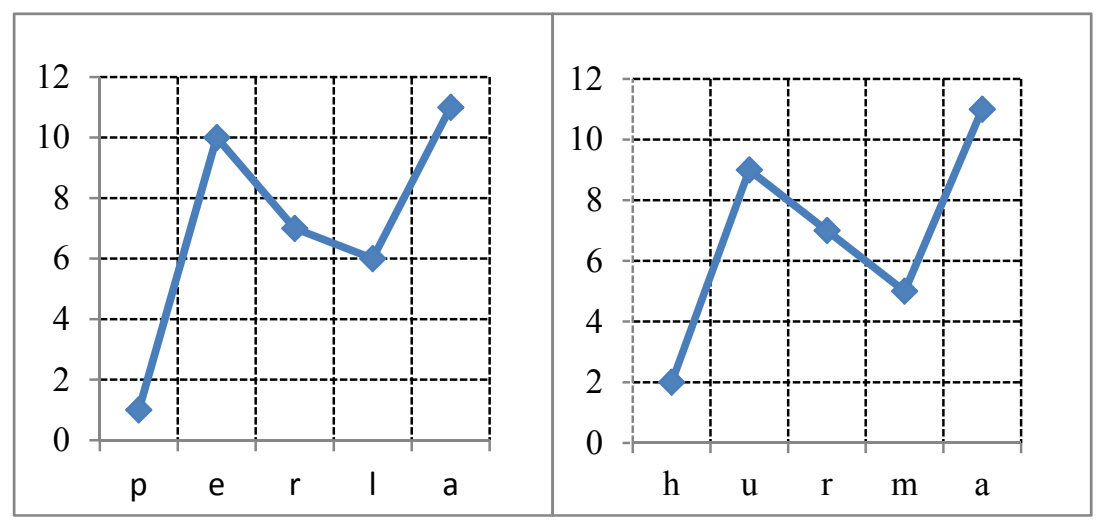

Figure 5. Sonority curve of the words perla and hurma

The syllabic divisions [per-la, hur-ma] are in full agreement with the Syllable Contact Law, the Sonority Dispersion Principle, and, in this way, the rule gains a more generalizing character to cover groups of two sonorous consonants between vowels, containing $/ \mathrm{r} /$ as the first constituent of the group. Other syllable divisions are in total compliance with the Sonority Theory.

\section{Conclusion}

The syllable structure in Albanian is complex owing to the vast range of consonant combinations, which makes it difficult to compile rules of the structure of its constituents. Standard Albanian poses fewer limitations than some other languages concerning the number of elements that can appear in the onset or the coda (Memushaj, 2015). For instance, there are complex words with four consonants in the onset such as shndrit /Jndrit/ 'glitter' (CCCCVC), whereas no more than three consonants can appear in the coda, as in kopsht $/ \mathrm{kop}[\mathrm{t} /$ 'garden' (CVCCC). If a language allows for such onsets and codas, it is hard to offer a once-and-for-all answer as to the syllable boundary. This is probably why Albanian phoneticians disagree on the solution to this problem.

This paper has focused on syllabification of bi-consonantal clusters in intervocalic position. We consider that the sonority theory offers better solutions to syllable boundary in Albanian. According to the data from our questionnaire, $82 \%$ of the subjects placed two consonants in the onset of the second syllable in [mi-sra], even though Albanian has no word starting with $s r$; thus, in this case the phonetic aspect overrules the phonotactic rule. This argument also holds for the groups $/ \mathrm{fk} /, / \mathrm{nt} /, / \mathrm{rj} /, / \mathrm{lj} /$ etc. The morphemic boundary and the word stress have no influence on syllabification in children's responses.

As it can be understood from the examples discussed above, if we focus on a detailed phonetic analysis of the articulation of a word or a certain group of sounds, relying on phonotactic criteria worsens the controversy on syllable boundary determination in Albanian. By contrast, if we resort to the Sonority Theory and the models we examined above, solutions that are more appropriate could be given: the rules of syllable boundary become clearer, more generalizing and simpler in practical application, by avoiding the exceptions for consonant groups in intervocalic position that possess the same sonority curve. Furthermore, we deem it necessary that experimental researches on such cases should be conducted in the future. However, for specific words in Albanian, the phonological factor, the morphological structure of a word and the role of stress may aid in determining syllable boundaries.

\section{References}

Beartsch, K. (2010). Coda Formation vs. Onset Maximization: Issues in the Syllabification of VCV Sequences. Language Research, 46 (1), 39-57. http://hdl.handle.net/10371/86461

Beci, B. (2004). Fonetika e gjuhës shqipe (The Phonetics of the Albanian language), Tirana: EDFA.

Belluscio, G., \& Rrokaj, Sh. (2011). Dizionario di equivalenza dei termini della linguistica italiano - albanese francese - inglese. Arcavacata di Rende - Tirana: Arbëria.

Carr, Ph., \& Honeybone, P. (2007). English phonology and linguistic theory: an introduction to issues, and to "Issues in English Phonology". Language Sciences, 29, 117-153.
https://doi.org/10.1016/j.langsci.2006.12.018 
Clements, G. N. (1990). The role of the sonority cycle in core syllabification. In J. Kingston \& M. E. Beckman (Eds.), Papers in Laboratory Phonology I (pp. 283-333). Cambridge: Cambridge University Press. https://doi.org/10.1017/CBO9780511627736.017 [also in Working Papers of the Cornell Phonetics Laboratory 2, 1-69, 1998.]

Clements, G. N. (1992). The sonority cycle and syllable organization. In W. U. Dressler, H. C. Luschutzky, O. E. Pfeiffer \& J. R. Rennison (Eds.), Phonologica 1998 (pp. 63-76). Cambridge: Cambridge University Press.

Crystal, D. (2008). A Dictionary of Linguistics and Phonetics (6th ed.). Oxford, UK: Blackwell Publishing Ltd.

Dodi, A. (2004). Fonetika dhe fonologiia e gjuhës shqipe (The Phonetics and Phonology of the Albanian language). Tirana: The Albanian Academy of Sciences.

Eddington, D., Treiman, R., \& Elzinga, D. (2013a). Syllabification of American English: Evidence from a Large-scale Experiment. Part I. Journal of Quantitative Linguistics, 20(1), 45-67. https://doi.org/10.1080/09296174.2012.754601

Eddington, D., Treiman, R., \& Elzinga, D. (2013b). Syllabification of American English: Evidence from a Large-scale Experiment. Part II. Journal of Quantitative Linguistics, 20(2), 75-93. https://doi.org/10.1080/09296174.2013.773136

Goldsmith, J. (2011). The Syllable. In J. Goldsmith, J. Riggle \& A. C. L. Yu (Eds.), The Handbook of Phonological Theory (2nd ed.). Oxford, UK: Wiley-Blackwell. https://doi.org/10.1002/9781444343069.ch6

Gouskova, M. (2001). Falling sonority onsets, loanwords and Syllable Contact. In M. Andronis, C. Ball, H. Elston \& S. Neuvel (Eds.), CLS 38: The Main Session. Papers from the $38^{\text {th }}$ Meeting of the Chicago Linguistic Society (Vol. 1, pp. 175-186). Chicago: CLS.

Gussenhoven, C., \& Jacobs, H. (2011). Understanding phonology. London: Hodder Education.

Kahn, D. (1976). Syllable-based generalizations in English phonology. Doctoral dissertation, MIT, Cambrige, MA. [Maximum Onset Principle: First, make the onset as long as it legitimately can be; then form a legitimate coda.].

Katamba, F. (1996). An Introduction to Phonology (Eighth impression). London: Longman.

Ladefoged, P., \& Johnson, K. (2011). A Course in Phonetics (6th ed.), Boston: Wadsworth, Cengage Learning.

Lodge, K. (2009). A Critical Introduction to Phonetics, London: Continuum International Publishing Group.

Memushaj, R. (2015). Fonetika e shqipes standarde (The Phonetics of Standard Albanian), Tirana: Infobotues, p. 141.

Murray, R. W., \& Vennemann, T. (1983). Sound change and syllable structure in Germanic phonology. In Language 59 (3), 514- 528.

Parker, S. G. (2002). Quantifying the sonority hierarchy. Doctoral dissertation, University of Massachusetts, Amherst.

Wright, R. (2004). A review of perceptual cues and cue robustness. In B. Hayes, R. M. Kirchner \& D. Steriade (Eds.), Phonetically Based Phonology (pp. 34-57). Cambridge: Cambridge University Press. https://doi.org/10.1017/CBO9780511486401.002

Xhaferaj, A. (2014). Rreth disa çështjeve të fonetikës së shqipes standarde (On Certain Issues of Standard Albanian Phonetics), in Memushaj R. Ndihmesa shkencore (Scientific Assistance), Vlora: Triptik, p. 66.

\section{Notes}

Note 1. In Albanian a hyphen (-) is used to designate the syllable boundary.

Note 2. The two letters [sh] represent one speech sound in Albanian, viz. [j].

Note 3 . The values on the vertical axis (0-12) of the Figures indicate the sonority scale of the Albanian sounds according to the 11-scale system presented by Dodi. 


\section{Appendix A}

Percentages of Responses Given by Subjects on the Syllabification of Bi-Consonantal Clusters in Intervocalic Position in Albanian Words

\begin{tabular}{|c|c|c|c|c|c|c|c|c|}
\hline \multirow{3}{*}{$\begin{array}{l}\text { Type of } \\
\text { cluster }\end{array}$} & \multirow{3}{*}{$\begin{array}{l}\text { Clusters } \\
\text { allowd in } \\
\text { onsets }\end{array}$} & \multirow{3}{*}{ Words } & \multicolumn{2}{|c|}{ Syllabification } & \multirow{3}{*}{$\begin{array}{lr}\text { Clusters not } \\
\text { allowd in } \\
\text { onsets }\end{array}$} & \multirow{3}{*}{ Words } & \multicolumn{2}{|c|}{ Syllabification } \\
\hline & & &. $\mathrm{CC}$ & C.C & & &. $\mathrm{CC}$ & C.C \\
\hline & & & $\%$ & $\%$ & & & $\%$ & $\%$ \\
\hline $\mathrm{O}+\mathrm{S}$ & $/ \mathrm{shr} /$ & mishra 'meats' & 70 & 30 & $/ \mathrm{sr} /$ & misra 'maize' & 82 & 18 \\
\hline $\mathrm{NS}+\mathrm{O}$ & $/ \mathrm{nk} /$ & banka 'bank' & 52 & 48 & $/ \mathrm{nt} /$ & fanta 'fruit juice' & 55 & 45 \\
\hline \multirow[t]{2}{*}{$\mathrm{S}+\mathrm{O}$} & & & & & /jz/ & vajzë 'girl' & 27 & 73 \\
\hline & & & & & $/ \mathrm{rk} /$ & arka 'ark' & 6 & 94 \\
\hline $\mathrm{O}+\mathrm{O}$ & $/ \mathrm{ft} /$ & nafta 'petrol' & 77 & 23 & $/ \mathrm{fk} /$ & pafka 'the stud' & 63 & 37 \\
\hline \multirow[t]{5}{*}{$\mathrm{S}+\mathrm{S}$} & $/ \mathrm{rrj} /$ & marrje 'reception' & 52 & 48 & $/ \mathrm{rj} /$ & larje 'washing' & 63 & 37 \\
\hline & $/ \mathrm{mj} /$ & pamje 'view' & 76 & 24 & $/ \mathrm{lj} /$ & dalje 'exit' & 87 & 13 \\
\hline & & & & & $/ \mathrm{rl} /$ & perla 'pearl' & 31 & 69 \\
\hline & & & & & /jr/ & ajri 'air' & 5 & 95 \\
\hline & $/ \mathrm{mr} /$ & zemra 'heart' & 60 & 40 & $/ \mathrm{rm} /$ & hurma 'the date fruit' & 31 & 69 \\
\hline
\end{tabular}

Note. $\mathrm{O}=$ obstruent, $\mathrm{S}=$ sonorant, $\mathrm{NS}=$ nasal sonorant. $\%$, percent of those who favoured .CC or C.C syllabification (e.g. $82 \%$ of the subjects syllabifies the word misra as [mi-sra], while $18 \%$ as [mis-ra]).

\section{Copyrights}

Copyright for this article is retained by the author, with first publication rights granted to the journal.

This is an open-access article distributed under the terms and conditions of the Creative Commons Attribution license (http://creativecommons.org/licenses/by/4.0/). 